Article

\title{
Rock Fragmentation Characteristics by TBM Cutting and Efficiency under Bi-Lateral Confinement
}

\author{
Yulong Chen ${ }^{1, *}$ and Chenpeng Song ${ }^{2,3, *}$ \\ 1 State Key Laboratory of Hydroscience and Engineering, Tsinghua University, Beijing 100084, China \\ 2 Department of Energy and Mineral Engineering, EMS Energy Institute and G3 Center, \\ Pennsylvania State University, University Park, PA 16802, USA \\ 3 Key Laboratory of Hydraulic and Waterway Engineering of the Ministry of Education, Chongqing Jiaotong \\ University, Chongqing 400074, China \\ * Correspondence: chen_yl@tsinghua.edu.cn (Y.C.); czs399@psu.edu (C.S.)
}

Received: 12 February 2018; Accepted: 13 March 2018; Published: 26 March 2018

\begin{abstract}
In this study, the mechanisms of rock breakage are assessed using tunnel boring machine (TBM) disc cutters under bi-axial pressure. Sequential indentation tests were conducted on granite specimens using a tri-axial testing platform. The morphology and volume of the fractured surface were measured and analyzed using a three-dimensional surface profilometer. An analysis of rock breaking growth and efficiency was performed as well. When the minor confining pressure $\left(\sigma_{1}\right)$ is constant, the results show that a larger difference in confining pressure leads to a larger volume of fractured surface, thereafter improving the rock-breaking efficiency even though the penetration energy is enlarged. On the other hand, when the major confining pressure $\left(\sigma_{2}\right)$ is constant, the penetration energy increases proportionally with the $\sigma_{1}$; however, the volume of fractured surface is decreased, and the breaking efficiency is attenuated as well.
\end{abstract}

Keywords: bi-lateral confinement; TBM disc cutters; rock fragmentation characteristics; morphology of fractured surface

\section{Introduction}

In recent years, a number of studies have been undertaken on the breaking process and characteristics of the rock fractures between tunnel boring machine (TBM) disc cutters. Based on two rock-breaking mechanisms [1,2], involving shear and tensile stress, some scholars demonstrated that, on the one hand, the horizontal shear stress between adjacent disc cutters is the main reason for the rock-breaking phenomenon. On the other hand, other researchers suggested that the breaking occurs due to the interpenetration of tension cracks caused by neighboring disc cutters. The content of a study regarding the characteristics of rock fragments can be also divided into two subsections: the first concentrates on the interior of the rock (e.g., uniaxial compressive strength, regarding joint, moisture content, and other efficient factors [3-8]), and the second focuses on external factors including tool size, shape, and machine operating parameters [9-16].

In addition, geo-stress increases in excavation of deep tunnels. An on-site investigation was performed by Gong et al. [17], and the findings showed that high ground stress could keep rock from breaking and did not produce plate cracking. When a local stress reaches a threshold, cracks are generated in the target rock mass. These cracks amplify the breaking of the rock under TBM disc cutters, leading to a reduction in the excavation index of the rock characteristics, and an improvement in the efficiency of rock breaking. Micro-fractures were observed in the rock on tunnel heading under high ground stress in on-site investigations, which were conducted by Yin et al. [18] and Tarkoy and Marconi [19]. 
Some scholars have recently studied the influence of confining pressure on the rock-breaking process and characteristics by using indoor experimental tests and numerical simulations. Bilgin et al. [20] studied the cutting efficiency of a boring machine tool under different confining pressures using a fracture analysis code (Franc2D) numerical method and an indoor test with a micro-rock cutting machine for rock. They reported that the penetration force gradually increased with the confining pressure. Innautrato et al. [21] utilized TBM disc cutters for a penetration test, in which the uniaxial compressive strength of a rock specimen reached $234 \mathrm{MPa}$, and the major confining pressure was $10 \mathrm{MPa}$. The experimental results showed that the increase of penetration force does not significantly increase confining forces in order to break the rock. Huang et al. [22] employed fast Lagrangian analysis of continua (FLAC) software to numerically simulate and analyze the effect of confining pressure on the crack development and the initiation of tension as well as fracture of the tool. The results demonstrated that a small increase of confining pressure caused the position of the maximum tensile stress to move significantly from the vertical thrust line and increased the crack vertical angle. Cook et al. [23], Liu et al. [24], and Ma et al. [25] reported that cracks tend to develop to the free surface once the confining pressure increases. It is worth mentioning that field investigations, laboratory tests, and numerical simulations can promote perceiving the mechanism of rock breaking of TBM in the presence of various confining pressures. However, most previous studies were undertaken as two-dimensional (2D) [23-25], imposing barriers to truly representing the breaking mechanism in three-dimensional (3D) spaces.

The development of a true triaxial test platform facilitates the accurate simulation of the rock-breaking process in different broken rock conditions. Ma et al. [25] studied the impact of different cutter spacings on the excavation's efficiency using a TBM cutter, in which a series of rock cutting tests were undertaken using five sets of cutter spacing. Balci [26] and Chang et al. [27] used disc cutters to perform a dynamic linear cutting test and analyzed the rock failure mechanism based on different rock conditions, disc cutters' parameters, loading parameters, and rock failure parameters, which were collected during the cutting process.

However, the bi-directional differential confining pressures were rarely taken into account. In order to investigate the influence of confining pressure on the rock-breaking characteristics of TBM, this paper concentrates on the assessment of the modes of rock breaking, and corresponding efficiency using a developed true triaxial test platform as well as a 3D surface profilometer.

\section{Test Methodology}

\subsection{Equipment}

\subsubsection{Penetration Platform}

The experiments were conducted using a developed true triaxial geophysical apparatus at Chongqing University, Chongqing, China, as shown in Figure 1 [28]. This apparatus is capable of performing mechanical and penetration experiments on samples designated as being under true triaxial stress conditions. 


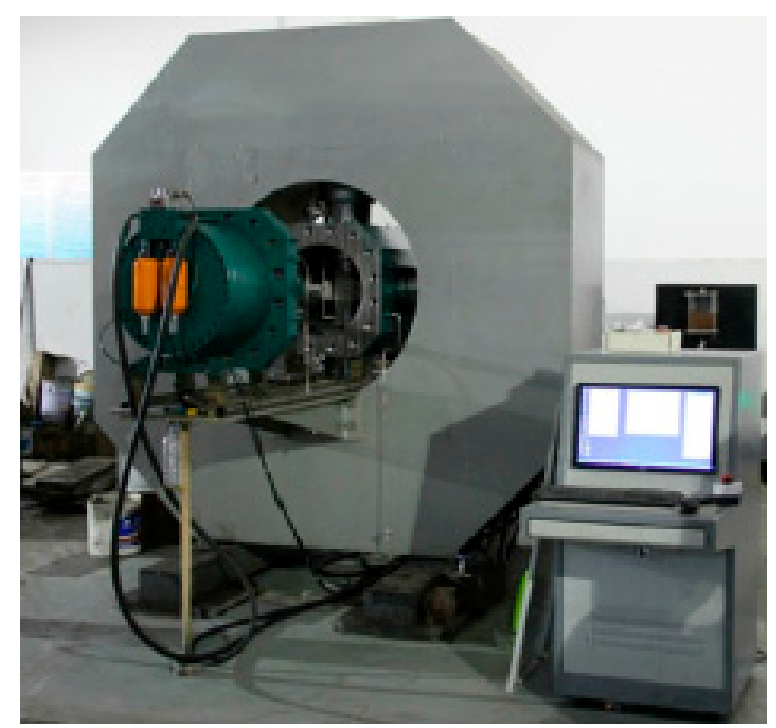

Figure 1. A true triaxial geophysical apparatus used in this study.

Moreover, loading is controlled by a hydraulic servo system, which can be used to record and save the penetration force through an external computer system. The tensile test machine frame is made of high-rigidity materials to guarantee the accuracy and reliability of the experiments. The system provides the disc cutters' penetration and required confining pressure as well.

\subsubsection{Tunnel Boring Machine Disc Cutters}

In order to investigate the characteristics of rock broken by TBM disc cutters under different confining pressures, a cross section of a typical disc cutter with a size of $561 \mathrm{~mm}$, a blade with a width of $13 \mathrm{~mm}$ and an angle of $20^{\circ}$, and a transition arc with radius of $3.5 \mathrm{~mm}$ is illustrated in Figure 2 . The tool was made of highly rigid material and was heat-treated to ensure minimal deformation during the testing.
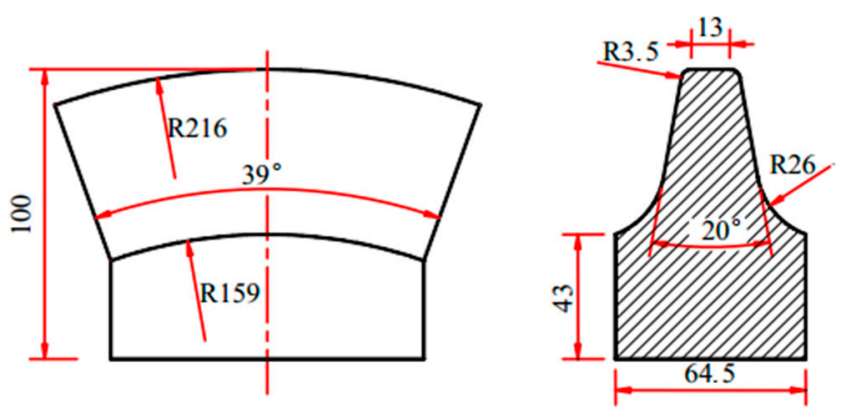

Figure 2. Dimensions and cross section of tunnel boring machine (TBM) disc cutters (mm).

\subsubsection{Surface Profilometer}

The dimensions of a fractured surface indicate the efficiency of the rock breaking. The rock breaking mode is derived from a morphological analysis. Furthermore, analysis of the size and morphology of a fractured surface is vital. In this study, a fixed-base surface profilometer (ST150) (Nanovea Company, Irvine, USA) was used to analyze the shape and size of a fractured surface between disc cutters in the presence of different mechanical conditions. As displayed in Figure 3, a surface profilometer mainly consists of a control system as well as a scanner, and is able to precisely post-process the scanner's result, involving the calculation of the volume of the fractured surface and 
a profile contour analysis. The scanner has a scanning range of $150 \mathrm{~mm} \times 150 \mathrm{~mm} \times 100 \mathrm{~mm}$ and a resolution of $0.5 \mu \mathrm{m}$, sufficient for surface measurements.

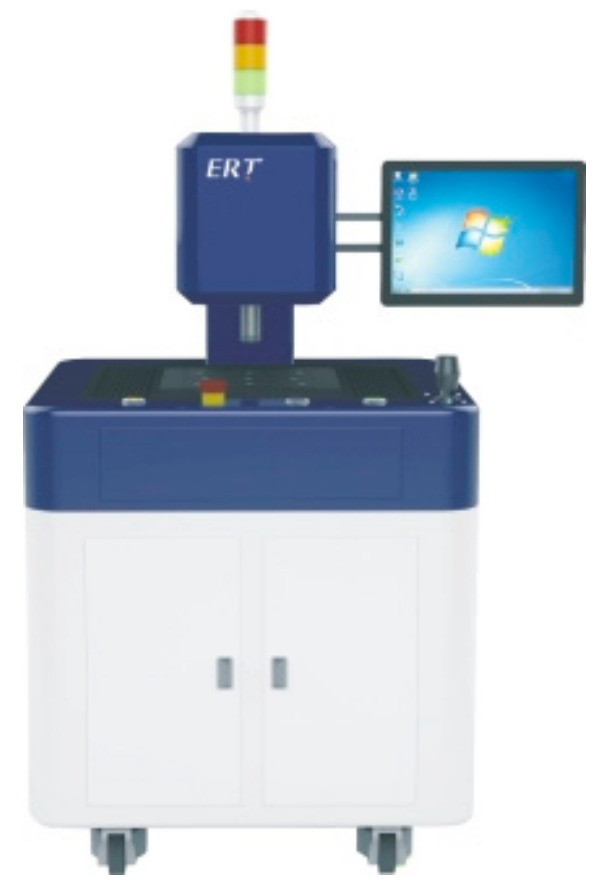

Figure 3. The fixed-base surface profilometer (ST150) used in this study (Nanovea Company, Irvine, USA).

\subsection{Specimen Preparation}

To investigate the breaking characteristics of rock and the efficiency of TBM disc cutters subjected to various biaxial confining pressures, a number of granite samples were prepared with high uniaxial compressive strength and brittleness. The specimens were prepared from the same rock to ensure that the mechanical properties of each specimen were consistent. The surface of each specimen was polished to eliminate negative effects. According to the standard code recommended by the International Society of Rock Mechanics (ISRM), uniaxial compression, Brazilian cleavage, and direct shear tests were undertaken on the specimens. The values of mechanical parameters were obtained as follows: uniaxial compressive strength $\sigma_{c}=94.8 \mathrm{MPa}$, tensile strength $\sigma_{t}=7.8 \mathrm{MPa}$, elastic modulus $E=22.3 \mathrm{MPa}$, Poisson's ratio $v=0.23$, internal friction angle $\varphi=49.2^{\circ}$, and cohesion $c=23 \mathrm{MPa}$.

A previous study performed by Yin et al. [29] reported that when the ratio of the radius of the plastic deformation zone to the minimum width of the specimen is less than $1 / 6$, the effect of size is negligible. Therefore, according to the billet cutting model, the relevant parameters are expressed as follows:

$$
\begin{gathered}
(1+\mu) \xi^{\left(1+K_{d}\right) / K_{d}}-\mu \xi^{\left(K_{p}-1\right) / K_{p}}=\gamma \\
K_{d}=\frac{1+\sin \varphi}{1-\sin \varphi} ; K_{p}=\frac{1+\sin \psi}{1-\sin \psi} \\
\mu=\frac{\lambda K_{p}}{K_{d}+K_{p}} \\
\lambda=\frac{\left(K_{p}-1\right)\left(K_{d}-1\right)+(1-2 v)\left(K_{p}+1\right)\left(K_{d}+1\right)}{2 K_{p}} \\
\xi=\frac{r_{*}}{t}
\end{gathered}
$$


where $\xi$ denotes the ratio of plastic deformation zone to penetration depth, $K_{p}$ represents an expansion coefficient, $K_{d}$ is a passive coefficient, $\mu$ is a friction coefficient for the crack surface, $\lambda$ denotes a lateral pressure coefficient, $r^{*}$ is the radius of plastic deformation zone, $t$ represents the penetration depth, and $\gamma$ is a constant for characterization of the size and shape of disc cutters.

Taking into account the loading capacity of the profilometer, the size of a granite sample was $250 \mathrm{~mm} \times 200 \mathrm{~mm} \times 100 \mathrm{~mm}$. Moreover, in the experiment the penetration depth was $6 \mathrm{~mm}$. Substituting the mechanical parameters of rock in Equation (1) into Equation (5), the radius of the plastic deformation zone was found to be $1.9 \mathrm{~mm}$, and its ratio to the minimum size of the specimen was far less than 1/6. According to the results achieved by Yin et al. [29], the size of the sample can be determined accordingly.

\subsection{Test Design and Procedure}

\subsubsection{Test Design}

Figure 4 schematically illustrates the penetration test for TBM disc cutters. The confining pressure is provided by a horizontal loading system, the penetration force of disc cutters is generated by a vertical loading system, and the vertical penetration process is controlled by force or displacement. In order to guarantee the safety of the test, the vertical penetration process is controlled by displacement.

As shown in Figure 4, minor confining pressure $\left(\sigma_{1}\right)$ and major confining pressure $\left(\sigma_{2}\right)$ are defined in the longitudinal and transverse directions. According to the different levels of bi-lateral confining pressure, $\sigma_{1}$ during penetration into granite is divided into three levels with values of 5.0, 10.0, and 15.0 MPa, respectively, and those values for $\sigma_{2}$ are 5.0, 10.0, 15.0, 20.0, and 25.0 MPa. As mentioned in Table 1, a total of 12 groups are tested. Simultaneously, the pressure drop is defined as the absolute difference between $\sigma_{2}$ and $\sigma_{1}$. Moreover, the distance between the two penetrations is $70 \mathrm{~mm}$ and the penetration rate is $0.5 \mathrm{~mm} / \mathrm{min}$. Gertsch et al. [30] showed that the penetration depth of the disc cutters during tunneling by TBM is generally $6-7 \mathrm{~mm}$ per week. Therefore, herein, the final penetration depth is taken to be $6 \mathrm{~mm}$.

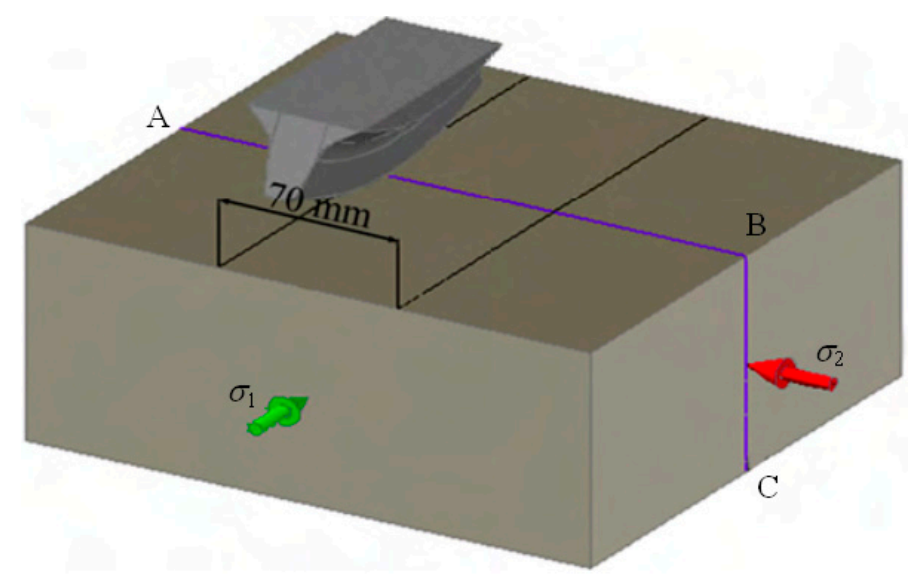

Figure 4. Schematic representation of penetration test for TBM disc cutters.

Table 1. Values of confining pressure for three different groups.

\begin{tabular}{cc}
\hline$\sigma_{\mathbf{1}} \mathbf{( \mathbf { M P a } )}$ & $\sigma_{\mathbf{2}} \mathbf{( \mathbf { M P a } )}$ \\
\hline 5 & $5,10,15,20,25$ \\
10 & $10,15,20,25$ \\
15 & $15,20,25$ \\
\hline
\end{tabular}




\subsubsection{Testing Process}

The testing process is divided into three main parts as follows:

1. Based on the true triaxial test, five steps are designed as follows:

1.1. To prevent stress between the pads and specimen surface, the contact surface and pad surface are properly coated before forwarding the specimen into the loading area, as shown in Figure 4.

1.2. Loads equal to $10 \mathrm{kN}$ are applied in the longitudinal and transverse directions. Confining loadings are proportionally applied to loads $\sigma_{2}$ and $\sigma_{1}$ to the set value when the previous loading is stabilized.

1.3. Once the confining pressure is loaded, the stress in the transverse direction is loaded to $100 \mathrm{~N}$ using the stress control to ensure that the loading unit in Z-direction is in full contact with the top of the disc cutters. After applying the load $(100 \mathrm{~N})$ in the transverse direction, displacement is used to control the penetration rate of the disc cutters while the penetration depth and force variations are recorded. The penetration energy is calculated by integrating the force values.

1.4. When the penetration depth reaches $6 \mathrm{~mm}$, penetration and recording the data should be stopped, and the stress in the transverse direction is unloaded. Once the unloading in the transverse direction has ended, the load in the longitudinal direction is removed.

1.5. The specimen is rotated and steps (2) to (5) are repeated for the second penetration test.

2. Scanning the fractured surface

The specimens, which are assessed by the penetration test, are placed on the tray upon the profilometer, the fractured surface generated after the penetration is scanned, and the built-in software is used to calculate the volume of the fractured surface.

3. Using a fully automatic rock cutting machine, the rock specimens are cut along the ABC plane (see Figure 4) to assess the development of internal cracks. In order to decrease the influence of cutting on the crack development, the thickness and speed of the cutting blade are set to $1 \mathrm{~mm}$ and $5 \mathrm{~cm} / \mathrm{min}$, respectively.

\section{Results}

\subsection{Fractured Surface Morphology Analysis}

Taking the fractured surface generated by the cutting of disc cutters of TBM at the confining pressure of 10-20 MPa as an example, a typical fractured surface is shown in Figure 5, in which the direction of the disc cutters' axis is indicated in the $X$-direction, the $Y$-direction is parallel to the grooving direction, and the $Z$-direction shows the penetration direction. Figure 5 shows the surface depth measured using an uncrushed original surface, which is marked with white and zero depth. In addition, dark blue represents the deep surface, and the maximum depth is $30 \mathrm{~mm}$. It can be seen that the fractured surface is mainly located within a range enclosed by the adjacent grooving and surface of an intact rock. The deepest point of the typical fractured surface is located roughly in the center, while its depth decreases from the middle to the edges. However, the variations in depth lead to the formation of small islands and partial deep pits. 


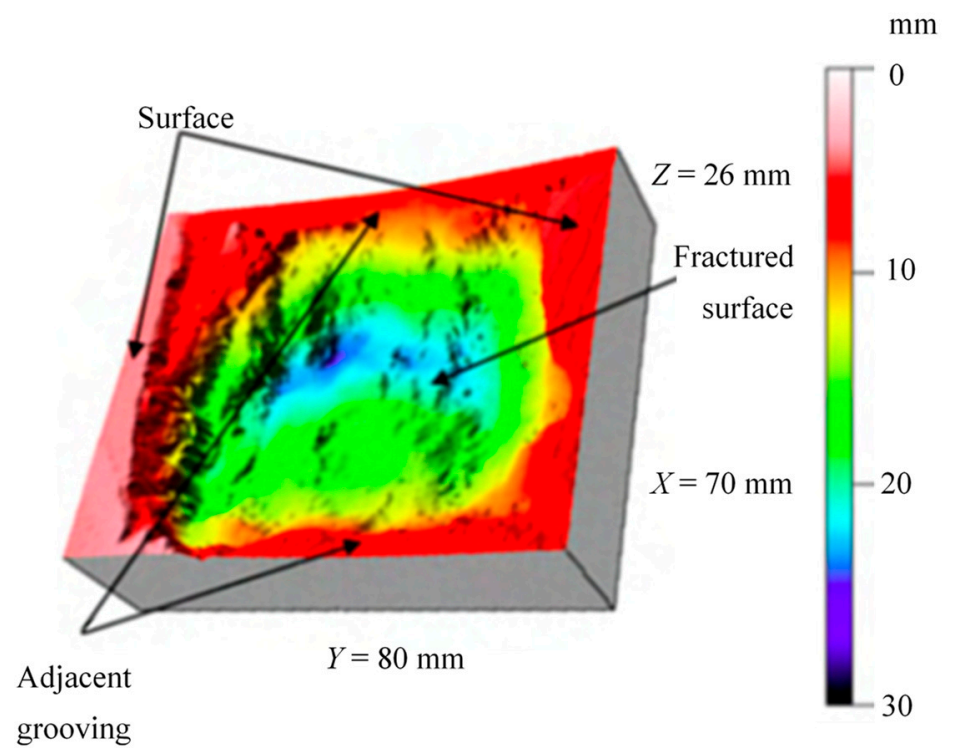

Figure 5. A typical fractured surface.

3.1.1. Variations of Fractured Surface with Increase of Major Confining Pressure while Minor Confining Pressure is Constant

Figure 6 illustrates the typical variation of a fractured surface, which $\sigma_{2}$ increases after conducting two penetrations, while $\sigma_{1}$ is constant $(5 \mathrm{MPa})$. Figure 6 a shows a fractured surface when $\sigma_{2}$ is $5 \mathrm{MPa}$. The deepest point is located in the middle; once the TBM disc cutters are sequentially penetrated, the maximum depth is measured $11.9 \mathrm{~mm}$. Additionally, an island is formed, and the deepest point of the fractured surface is on both sides of the island. The volume of the fractured surface is roughly $25.634 \mathrm{~mm}^{3}$, which is calculated by the built-in software. The fractured surface after two penetrations is small, indicating that the breaking effect under the confining pressure is not remarkable. Furthermore, $\sigma_{2}$ increases to $10 \mathrm{MPa}$. As shown in Figure 6b, the yellow part has a depth in the range of 12 to $16 \mathrm{~mm}$, which has been increased in comparison with Figure 6a. Furthermore, it is revealed that the bottom of the fractured surface contains a high peak and a low pit in the X-direction, in which the maximum depth and volume are about $16.2 \mathrm{~mm}$ and $33.682 \mathrm{~mm}^{3}$, respectively. Increases in the maximum depth and volume indicate that the rock breaking tends to grow along the depth direction when $\sigma_{2}$ increases from 5 to $10 \mathrm{MPa}$, and the effect of rock breaking under $10 \mathrm{MPa}$ confining pressure is improved as well.

As $\sigma_{2}$ increases to $15 \mathrm{MPa}$, the size of the fractured surface in the $Y$-direction increases to $80 \mathrm{~mm}$, as displayed in Figure 6c. An island is formed in the middle of the fractured surface, in which the top of the island has a depth of $15 \mathrm{~mm}$. The maximum depth of the fractured surface reaches $22.1 \mathrm{~mm}$. The bottom of the fractured surface is relatively flat, with a depth of $15 \mathrm{~mm}$. Meanwhile, the volume of the fractured surface increases sharply to $61.370 \mathrm{~mm}^{3}$. This indicates that when $\sigma_{1}$ is $5 \mathrm{MPa}$, the crushing amount of rock mass between disc cutters is increased 1.8 times once $\sigma_{2}$ increases from 10 to $15 \mathrm{MPa}$; when $\sigma_{2}$ increases to $20 \mathrm{MPa}$, the shape of the fractured surface is similar to the counterpart. When $\sigma_{2}$ is $15 \mathrm{MPa}$, the maximum depth is $21.8 \mathrm{~mm}$, and the volume decreases slightly to $58.768 \mathrm{~mm}^{3}$. When $\sigma_{2}$ increases to $25 \mathrm{MPa}$, as depicted in Figure $6 \mathrm{e}$, the fractured surface represents a typical spherical morphology: the middle is low and the depth gradually decreases towards the edges. The maximum depth and volume reach $27.1 \mathrm{~mm}$ and $87.031 \mathrm{~mm}^{3}$, respectively. It can be seen that the breaking efficiency of disc cutters of TBM is at the maximum when $\sigma_{1}$ and $\sigma_{2}$ are 5 and $25 \mathrm{MPa}$, respectively. Based on the achieved results, with the increase of $\sigma_{2}$, the rock is broken more effectively after performing two penetrations. 


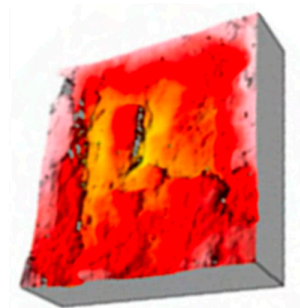

(a) $\sigma_{2}=5 \mathrm{MPa}$

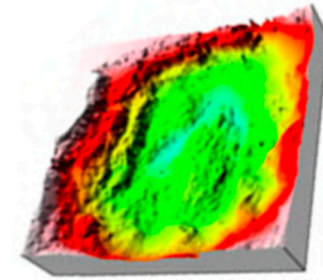

(d) $\sigma_{2}=20 \mathrm{MPa}$

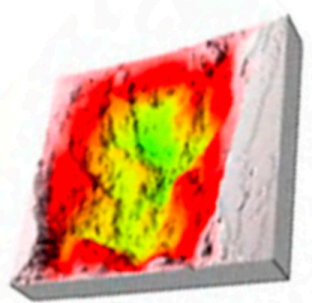

(b) $\sigma_{2}=10 \mathrm{MPa}$

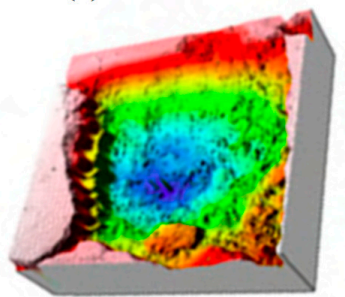

(e) $\sigma_{2}=25 \mathrm{MPa}$

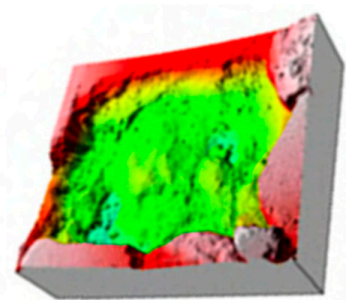

(c) $\sigma_{2}=15 \mathrm{MPa}$

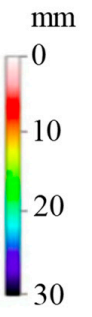

Figure 6. Variations of fractured surface with increase of major confining pressure $\left(\sigma_{2}\right)$, while minor confining pressure $\left(\sigma_{1}\right)$ is constant at $5 \mathrm{MPa}$.

3.1.2. Variation of Fractured Surface once Minor Confining Pressure Increases, while Major Confining Pressure is Constant

Figure 7 shows the typical variation of a fractured surface when $\sigma_{1}$ increases after two penetrations, while $\sigma_{2}$ is constant at a value of $5 \mathrm{MPa}$. As shown in Figure 7a, the maximum depth reaches $27.1 \mathrm{~mm}$ when $\sigma_{1}$ is $5 \mathrm{MPa}$. The fractured surface tends to be a basin shape, and the broken range in the $Y$-direction reaches $80 \mathrm{~mm}$. As a result, the volume of the fractured surface is equal to $87.031 \mathrm{~mm}^{3}$. Once $\sigma_{1}$ is increased to $10 \mathrm{MPa}$, the fractured surface is a typical basin-like shape as well. However, a small island emerged in the lower right corner, and the range of crushing in the $Y$-direction slightly decreased to $73 \mathrm{~mm}$. The maximum depth of the fractured surface also drops to $24.8 \mathrm{~mm}$, and the corresponding volume decreases to $73.908 \mathrm{~mm}^{3}$ as well; once $\sigma_{1}$ increases to a value of $15 \mathrm{MPa}$, as illustrated in Figure 7c, the breaking in the $Y$-direction reaches $88 \mathrm{~mm}$, and its maximum depth is equal to $24.5 \mathrm{~mm}$. The fractured surface with a depth greater than $18 \mathrm{~mm}$ is small and often found near the center. The formed island is not fully broken, thus the volume of fractured surface is further reduced to $65.388 \mathrm{~mm}^{3}$. In conclusion, the volume of the fracture's surface tends to gradually decrease with the confining pressure, while $\sigma_{2}$ is constant.

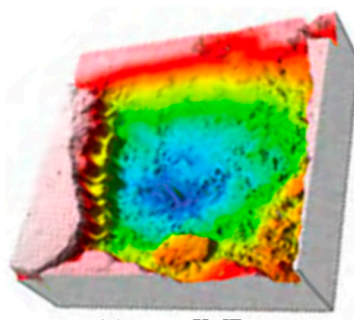

(a) $\sigma 1=5 \mathrm{MPa}$

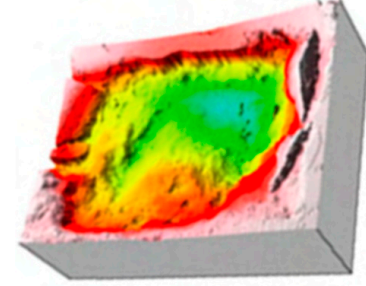

(c) $\sigma_{1}=15 \mathrm{MPa}$

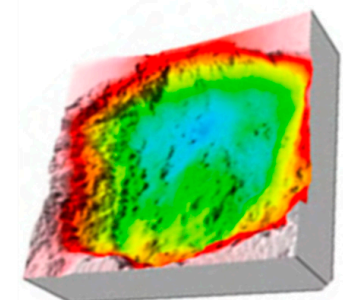

(b) $\sigma=10 \mathrm{MPa}$

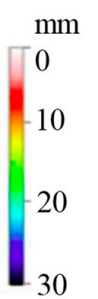

Figure 7. Variations of fractured surface with increase of $\sigma_{1}$ while $\sigma_{2}$ is constant at $25 \mathrm{MPa}$. 


\subsection{Crack Development between Disc Cutters}

3.2.1. Variations of Crack Development with Increase of Major Confining Pressure while Minor Confining Pressure is Constant

As shown in Figure 8a, there is no obvious crack development in the cross section between two plastic deformation zones when the confining pressure is $5 \mathrm{MPa}$. The fractured surface contains an approximate triangular shape, and the breaking surface is straight and flat. A crack could develop due to the combined action of shear failure and surface tension. Simultaneously, a crack with a certain deflection angle appears below each plastic deformation zone, and the broken area is relatively small. As $\sigma_{2}$ increases to $10 \mathrm{MPa}$, the shape of the fractured surface varies and becomes nearly semilunar-shaped with an uneven depth, as illustrated in Figure $8 \mathrm{~b}$. At the same time, when $\sigma_{2}$ is $5 \mathrm{MPa}$, the pit is slightly deeper. A crack starts to grow in a plastic defamation zone, and then crack propagation forms, leading to an interconnected crack between the two plastic deformation zones. Additionally, when $\sigma_{2}$ increases to $15 \mathrm{MPa}$, the depth of the fractured surface increases slightly, the crack initiation angle decreases somewhat, and the deflection angle increases sharply. Accordingly, breaking is simultaneously made by the internal tensile cracks.

When $\sigma_{2}$ increases to $20 \mathrm{MPa}$, the shape of the fractured surface is similar to the surface when the confining pressure reaches 5-10 MPa, as depicted in Figure $8 \mathrm{~d}$. The fractured surface is also likely to be formed by internal tensile cracks. However, the level of crack development is low, and there are only two internal cracks besides the cracks formed between the disc cutters. When $\sigma_{2}$ increases to $25 \mathrm{MPa}$, the shape of the fracture's surface is similar to the surface created by those two types of confining pressures, as shown in Figure 8e. However, it can be seen that when the depth is large, the crack development in the plastic deformation zone is not clear enough. Moreover, a new type of crack is observed that does not originate with the plastic deformation zone below the disc cutters. The cracks are randomly distributed within the rock with varying lengths. This type of crack has been reported in a previous study performed by Yin et al. [29] as well, and leads to breaks.

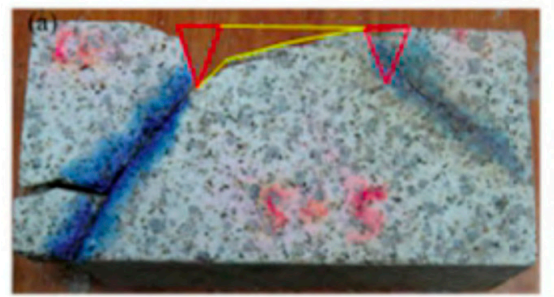

(a) $\sigma_{2}=5 \mathrm{MPa}$

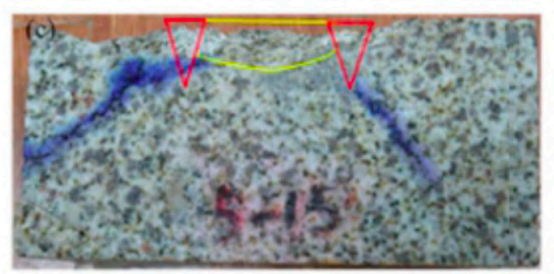

(c) $\sigma_{2}=15 \mathrm{MPa}$

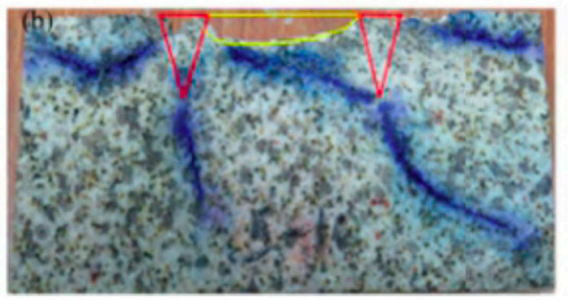

(b) $\sigma_{2}=10 \mathrm{MPa}$

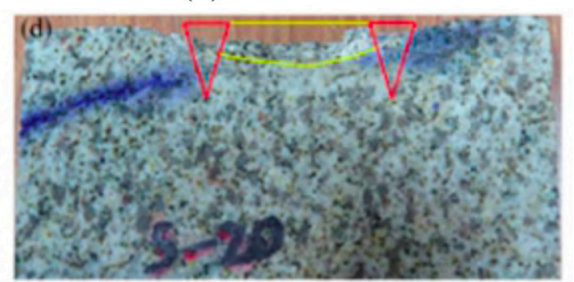

(d) $\sigma_{2}=20 \mathrm{MPa}$

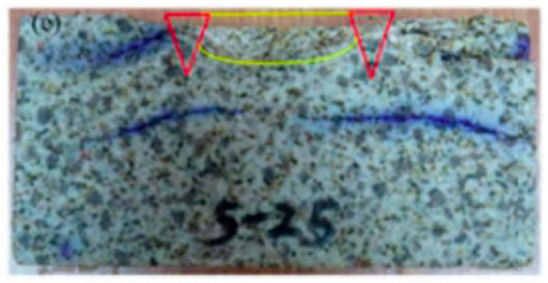

(e) $\sigma_{2}=25 \mathrm{MPa}$

Figure 8. Crack development in the cross section with increase of $\sigma_{2}$, while $\sigma_{1}$ is $5 \mathrm{MPa}$. 
3.2.2. Variation of Crack Development with Increase of Minor Confining Pressure while Major Confining Pressure is Constant

When $\sigma_{2}$ is equal to $20 \mathrm{MPa}$, the variation of the crack growth with the increase of $\sigma_{1}$ is displayed in Figure 9. When $\sigma_{1}$ is equal to $5 \mathrm{MPa}$, the profile of the fractured surface is low in the middle and very close to the edges. When $\sigma_{1}$ increases to $10 \mathrm{MPa}$, the shape is roughly similar to when $\sigma_{1}$ is only $5 \mathrm{MPa}$, as shown in Figure 9b. Although the lowest point is deeper than the former situation, the contour is deeper when the confining pressure is 5-20 MPa. Additionally, there is an obvious crack connecting two plastic deformation zones below the fractured surface. Therefore, when the confining pressure is $10-20 \mathrm{MPa}$, the increase in $\sigma_{1}$ leads to a decrease in crushing depth, preventing the propagation of the cracks from the top to the bottom, and resulting in shallow and small fractured surfaces. Figure $9 \mathrm{c}$ illustrates that when $\sigma_{1}$ increases to $15 \mathrm{MPa}$, the range of crack development is larger than that of the confining pressure of 10 and $20 \mathrm{MPa}$. In addition, the fractured surfaces between disc cutters are clearly varied. These showed similar shapes-low in the middle and high towards the edges-and there are obvious internal cracks, directly propagating. Therefore, the increase in $\sigma_{1}$ prevents crack development in the depth direction, resulting in a decrease in depth of the fractured surface as well. The increase of $\sigma_{1}$ causes the cracking to happen near the shallow surface.

The trend of the variation of cracks with confining pressure has verified the trend of the morphology of fractured surface with the confining pressure. When $\sigma_{1}$ is constant, more rocks tend to be broken after two penetrations with the increase of $\sigma_{2}$. When $\sigma_{2}$ is constant, the size of the fractured surface tends to gradually reduce with the decrease in confining pressure.

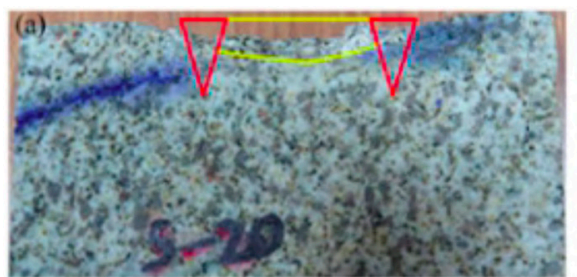

(a) $\sigma_{1}=5 \mathrm{MPa}$

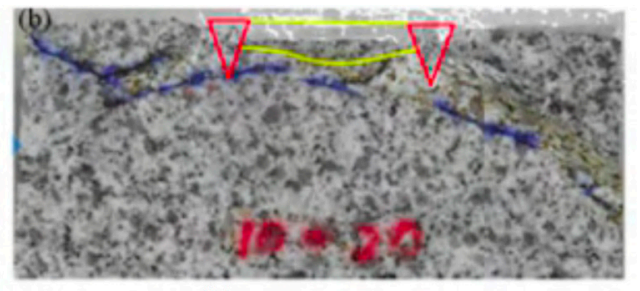

(b) $\sigma_{\mathrm{l}}=10 \mathrm{MPa}$

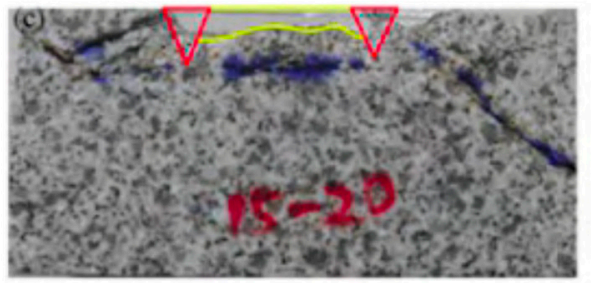

(c) $\sigma_{1}=15 \mathrm{MPa}$

Figure 9. Crack development in the cross section with increase of $\sigma_{1}$, while $\sigma_{2}$ is $20 \mathrm{MPa}$.

\section{Discussion}

The specific energy for cutting is a key indicator for evaluating the efficiency of rock breaking, which is defined as the energy it takes to crush a volumetric unit of rock, in $\mathrm{MJ} / \mathrm{m}^{3}$. Specific energy is calculated via dividing the cutting energy by the volume of breaking rock [31].

The two key indicators describing the efficiency of energy consumption are the cutting energy and broken volume. The relationship between the cutting energy consumption and $\sigma_{2}$ and $\sigma_{1}$ is analyzed in combination with the penetration energy and volume of fractured surface at different confining pressure levels, as shown in Figures 10 and 11. 


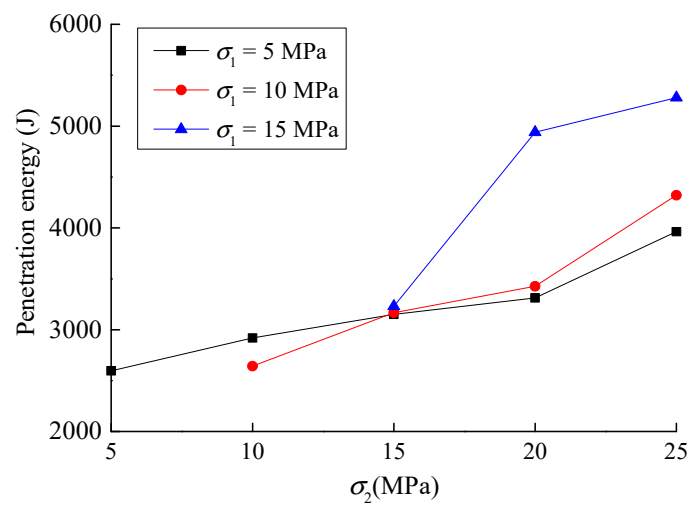

(a) Penetration energy varies with $\sigma_{2}$

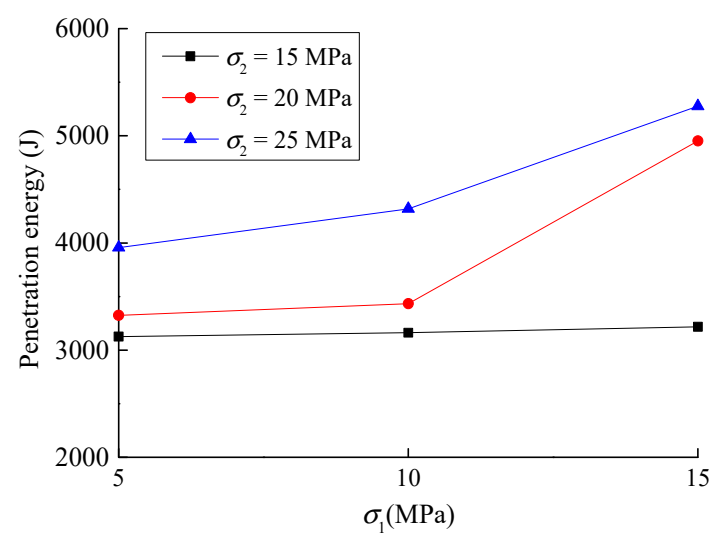

(b) Penetration energy varies with $\sigma_{1}$

Figure 10. Penetration energy under different confining pressure levels.

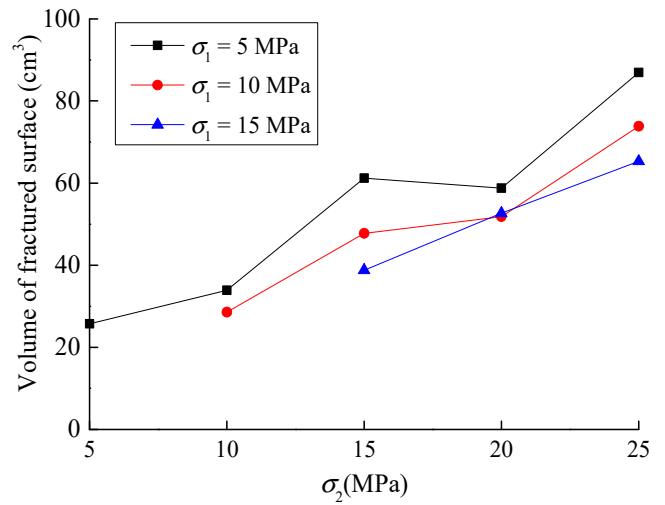

(a) Volume of fractured surface varies with $\sigma_{2}$

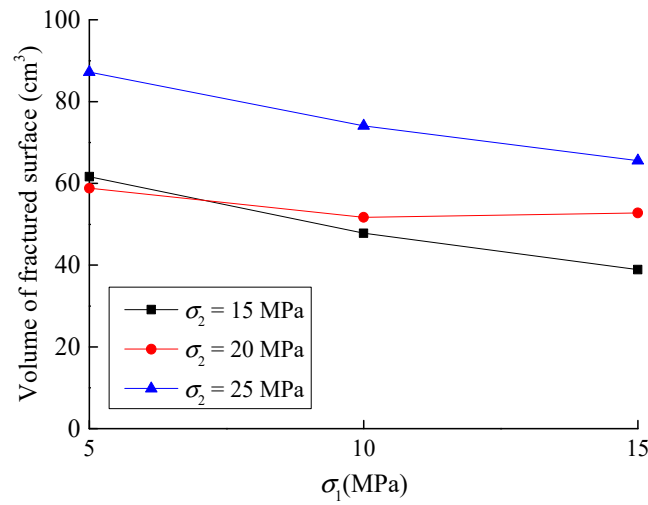

(b) Volume of fractured surface varies with $\sigma_{1}$

Figure 11. Volume of fractured surface under different confining pressures.

\subsection{Penetration Energy under Different Confining Pressures}

When $\sigma_{1}$ is constant, the total energy consumption during two penetrations of granite samples with the increase of confining pressure is shown in Figure 10a. When the confining pressure is $5 \mathrm{MPa}$, the penetration energy reaches over $2500 \mathrm{~J}$; when $\sigma_{2}$ increases, the energy consumption gradually increases with $\sigma_{2}$. When $\sigma_{1}$ reaches $10-15 \mathrm{MPa}$, the overall trend is similar to that of $\sigma_{1}$ (equal to $5 \mathrm{MPa}$ ). When $\sigma_{2}$ is constant, as the discrepancy between confining pressures decreases, the total energy is shown in Figure 10b. It can be seen that the energy consumption in the two penetration processes continuously increases with $\sigma_{1}$.

\subsection{Volume of the Fractured Surface under Different Confining Pressures}

When $\sigma_{1}$ is constant, the volume of the fractured surface clearly increases with the increase of $\sigma_{2}$, when the depth of penetration and the corresponding distance between disc cutters are constant. Therefore, with the increase in confining pressure, the corresponding rock breaking efficiency improves as well.

With the decrease in confining pressure, the rock between the grooves develops from tension failure in the deep bottom to shear failure near the surface, and the crushing degree decreases with the reduction in confining pressure. In summary, the reduction of the confining pressure may reduce the crushing of the rock mass between the grooves. 


\subsection{Breaking Efficiency under Different Confining Pressures}

The energy consumed during the two penetrations continuously increases with the increase of $\sigma_{2}$, and the volume of the fractured surface increases as well. The between describing the variation trend of the specific energy and $\sigma_{2}$ is difficult to determine based only on the cutting specific energy. As shown in Figure 12a, the specific energy decreases with the increase in $\sigma_{2}$, reflecting that the increase of $\sigma_{2}$ tends to increase the rock-breaking efficiency.

However, with the increase of $\sigma_{1}$, the cutting energy increases, while the volume of the fractured surface rapidly decreases. Combined with Equation (5), the energy consumed to form the crushed body per unit volume increases due to the increase in $\sigma_{1}$. The increase in $\sigma_{1}$ causes the TBM disc cutters to have reduced rock-breaking efficiency. As illustrated in Figure 12b, the cutting energy consumption shows an increasing trend with the decrease in confining pressure, and the reduction in confining pressure leads to a decrease in the efficiency of the disc cutters.

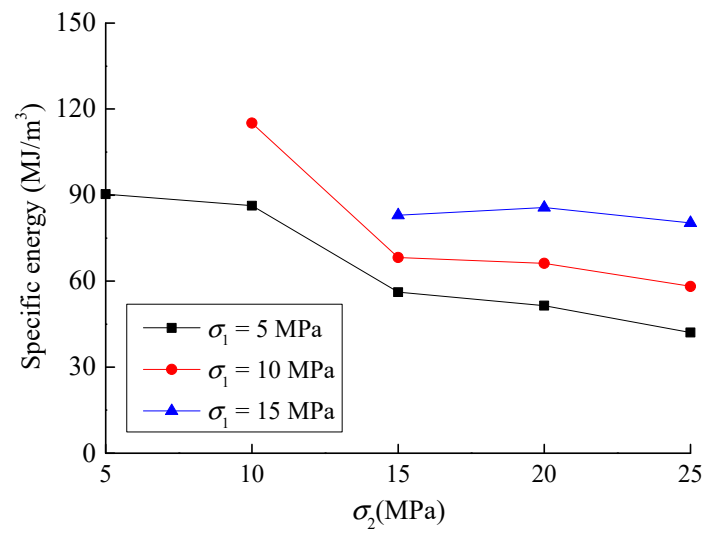

(a) Variations of specific energy with $\sigma_{2}$

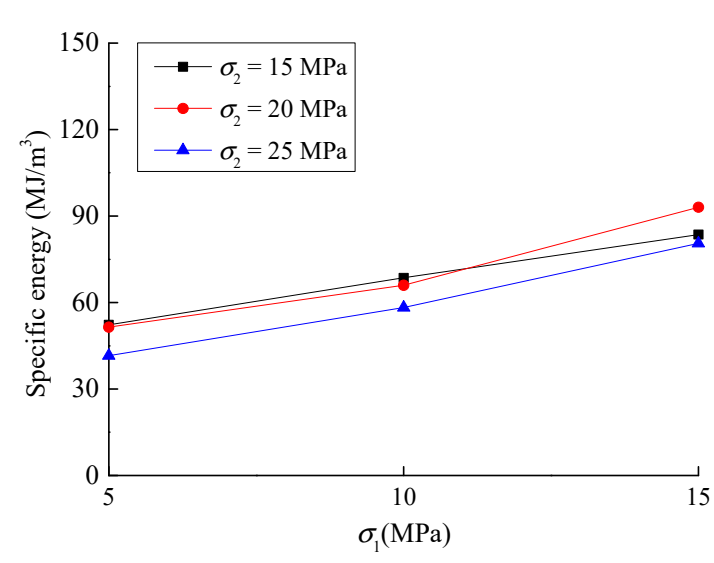

(b) Variations of specific energy with $\sigma_{1}$

Figure 12. Specific energy efficiency under different confining pressures.

\section{Conclusions}

In order to study the characteristics of rock breaking and corresponding efficiency under different confining pressures, TBM penetration tests under bi-lateral confining pressure were conducted and the volume and morphology of fractured surface were assessed as well. Based on the results the following conclusions are drawn:

1. The fractured surface gradually developed when $\sigma_{1}$ was constant and $\sigma_{2}$ increased. The rock crushing mechanism varied from the shear failure in the shallow surface to the tensile failure in the bottom, and the efficiency of rock breaking gradually increased.

2. The depth and volume of the fractured surface gradually decreased, and the failure mode varied from tensile failure to shear failure, resulting in a decrease in rock-breaking efficiency when $\sigma_{2}$ was constant and $\sigma_{1}$ increased.

3. When $\sigma_{1}$ was constant, the energy consumption efficiency gradually increased with an increase in $\sigma_{2}$. Although some fluctuations were observed, the overall energy consumption increased with the increase in $\sigma_{2}$. When $\sigma_{2}$ was constant, the energy consumption gradually increased with an increase in $\sigma_{1}$.

4. Edge effects played a significant role in experimental performance. Large-scale sample tests provided insight into the characteristics of rock breaking. In the present study, whether it affects the experimental results or not is out of our research area. We plan to survey the edge effect in a future study. 
Acknowledgments: The authors would like to thank the China Postdoctoral Science Foundation (Grant No. 2017M620048), and the National Natural Science Foundation of China (Grant No. 51604051) for funding this study.

Author Contributions: Y.C. conceived, designed and performed the experiments; C.S. analyzed the data.

Conflicts of Interest: The authors declare no conflict of interest.

\section{References}

1. Ozdemir, L.; Wang, F.D. Mechanical Tunnel Boring Prediction and Machine Design; Colorado School of Mines: Golden, CO, USA, 1979.

2. Gertsch, R.E. Rock Toughness and Disc Cutting; University of Missouri: Columbia, MO, USA, 2000.

3. Eftekhari, M.; Baghbanan, A.; Bagherpour, R. The effect of fracture patterns on penetration rate of TBM in fractured rock mass using probabilistic numerical approach. Arab. J. Geosci. 2013, 7, 5321-5331. [CrossRef]

4. Bakar, M.Z.A.; Gertsch, L.S.; Rostami, J. Evaluation of fragments from disc cutting of dry and saturated sandstone. Rock Mech. Rock Eng. 2014, 47, 1891-1903. [CrossRef]

5. Gong, Q.-M.; Zhao, J. Development of a rock mass characteristics model for TBM penetration rate prediction. Int. J. Rock Mech. Min. Sci. 2009, 46, 8-18. [CrossRef]

6. Yagiz, S. Utilizing rock mass properties for predicting TBM performance in hard rock condition. Tunn. Undergr. Space Technol. 2008, 23, 326-339. [CrossRef]

7. Gong, Q.-M.; Zhao, J.; Jiao, Y.-Y. Numerical modeling of the effects of joint orientation on rock fragmentation by TBM cutters. Tunn. Undergr. Space Technol. 2005, 20, 183-191. [CrossRef]

8. Gong, Q.-M.; Zhao, J. Influence of rock brittleness on TBM penetration rate in Singapore granite. Tunn. Undergr. Space Technol. 2007, 22, 317-324. [CrossRef]

9. Wang, S.Y.; Sloan, S.W.; Liu, H.Y.; Tang, C.A. Numerical simulation of the rock fragmentation process induced by two drill bits subjected to static and dynamic (impact) loading. Int. J. Rock Mech. Min. Sci. 2011, 44, 317-332. [CrossRef]

10. Goldsmith, W.; Wu, W. Response of rocks to impact loading by bars with pointed ends. Rock Mech. 1981, 13, 157-184. [CrossRef]

11. Tan, Q.; Xu, Z.-J.; Xia, Y.-M.; Zhang, K. Numerical study on mode of breaking rock by TBM cutter in two cutting orders. J. Cent. South Univ. 2012, 43, 940-946.

12. Hadi, H.; Mohammad, F.M.; Kourosh, S. Simulating the effects of disc erosion in TBM DISC cutters by a semi-infinite DDM. Arab. J. Geosci. 2014, 6, 3915-3927.

13. Huo, J.; Hou, N.; Sun, W.; Wang, L.; Dong, J. Analyses of dynamic characteristics and structure optimization of tunnel boring machine cutter system with multi-joint surface. Nonlinear Dyn. 2017, 87, 237-254. [CrossRef]

14. Huo, J.; Zhu, D.; Hou, N.; Sun, W.; Dong, J. Application of a small-timescale fatigue, crack-growth model to the plane stress/strain transition in predicting the lifetime of a tunnel-boring-machine cutter head. Eng. Fail. Anal. 2016, 71, 11-30. [CrossRef]

15. Huo, J.; Wu, H.; Sun, W.; Zhang, Z.; Wang, L.; Dong, J. Electromechanical coupling dynamics of TBM main drive system. Nonlinear Dyn. 2017, 90, 2687-2710. [CrossRef]

16. Huo, J.; Wang, W.; Sun, W.; Ling, J.; Dong, J. The multi-stage rock fragmentation load prediction model of tunnel boring machine cutter group based on dense core theory. Int. J. Adv. Manuf. Technol. 2017, 90, 277-289. [CrossRef]

17. Gong, Q.M.; She, Q.R.; Hou, Z.S.; Jiang, H.; Peng, Q. Experimental study of TBM penetration in marble rock mass under high geostress. Chin. J. Rock Mech. Eng. 2010, 29, 2522-2532.

18. Yin, L.J.; Gong, Q.M.; Zhao, J. Study on rock mass boreability by TBM penetration test under different in situ stress conditions. Tunn. Undergr. Space Technol. 2014, 43, 413-425. [CrossRef]

19. Tarkoy, P.J.; Marconi, M. Difficult rock comminution and associated geological conditions. In Proceedings of the International Symposium: Tunnelling '91, London, UK, 14-18 April 1991; pp. 195-207.

20. Bilgin, N.; Tuncdemir, H.; Balci, C.; Copur, H.; Eskikaya, S. A model to predict the performance of tunneling machines under stressed conditions. In Proceedings of the AITES-ITA 2000 World Tunnel Congress, Durban, South Africa, 13-17 May 2000; pp. 47-54.

21. Innaurato, N.I.; Oggeri, C.; Oreste, P.P.; Vinai, R. Experimental and numerical studies on rock breaking with TBM tools under high stress confinement. Rock Mech. Rock Eng. 2007, 40, 429-451. [CrossRef] 
22. Huang, H.; Damjanal, B.; Detournay, E. Normal wedge indentation in rocks with lateral confinement. Rock Mech. Rock Eng. 1998, 31, 81-94. [CrossRef]

23. Cook, N.G.; Hood, M.; Tsai, F. Observation of crack growth in hard rock loaded by an indenter. Int. J. Rock Mech. Min. Sci. 1984, 21, 97-107. [CrossRef]

24. Liu, H.Y.; Kou, S.Q.; Lindqvist, P.A.; Tang, C.A. Numerical simulation of the rock fragmentation process induced by indenters. Int. J. Rock Mech. Min. Sci. 2002, 39, 491-505. [CrossRef]

25. Ma, H.-S.; Yin, L.-J.; Ji, H.-G. Numerical study of the effect of confining stress on rock fragmentation by TBM cutters. Int. J. Rock Mech. Min. Sci. 2011, 48, 1021-1033. [CrossRef]

26. Balci, C. Correlation of rock cutting tests with field performance of a TBM in a highly fractured rock formation: A case study in Kozyatagi-Kadikoy metro tunnel, Turkey. Tunn. Undergr. Space Technol. 2009, 24, 423-435. [CrossRef]

27. Chang, S.H.; Choi, S.W.; Bae, G.J. Performance prediction of TBM disc cutting on granitic rock by the linear cutting test. Tunn. Undergr. Space Technol. 2006, 21, 271. [CrossRef]

28. Li, M.H.; Yin, G.Z.; Xu, J.; Li, W.; Song, Z.; Jiang, C. A novel true triaxial apparatus to study the geomechanical and fluid flow aspects of energy exploitations in geological formations. Rock Mech. Rock Eng. 2016, 49, 4647-4659. [CrossRef]

29. Yin, L.J.; Gong, Q.M.; Ma, H.S.; Zhao, J.; Zhao, X.B. Use of indentation tests to study the influence of confining stress on rock fragmentation by a TBM cutter. Int. J. Rock Mech. Min. Sci. 2014, 72, 261-276. [CrossRef]

30. Gertsch, R.; Gertsch, L.; Rostami, J. DISC cutting tests in Colorado red granite: Implications for TBM performance prediction. Int. J. Rock Mech. Min. Sci. 2007, 44, 238-246. [CrossRef]

31. Bejari, H.; Hamidi, J.K. Simultaneous effects of joint spacing and orientation on TBM cutting efficiency in jointed rock masses. Rock Mech. Rock Eng. 2013, 46, 897-907. [CrossRef]

(C) 2018 by the authors. Licensee MDPI, Basel, Switzerland. This article is an open access article distributed under the terms and conditions of the Creative Commons Attribution (CC BY) license (http:/ / creativecommons.org/licenses/by/4.0/). 